CLINICAL STUDY

\title{
Long-acting octreotide treatment causes a sustained decrease in ghrelin concentrations but does not affect weight, behaviour and appetite in subjects with Prader-Willi syndrome
}

\author{
Kathleen De Waele, Stacey L Ishkanian, Roberto Bogarin, Charmaine A Miranda ${ }^{1}$, Mohammad A Ghatei ${ }^{2}$, \\ Stephen R Bloom ${ }^{2}$, Danièle Pacaud ${ }^{3}$ and Jean-Pierre Chanoine \\ Endocrinology and Diabetes Unit, Room K4-212, British Columbia's Children's Hospital, University of British Columbia, 4480 Oak Street, Vancouver, \\ Canada BC V6H 3V4, ${ }^{1}$ Department of Psychology, British Columbia's Children's Hospital, University of British Columbia, Vancouver, Canada BC V6H \\ 3V4, ${ }^{2}$ Department of Metabolic Medicine, Imperial College Faculty of Medicine, Hammersmith Campus, London W12 ONN, UK and ${ }^{3}$ Division of \\ Endocrinology, Alberta Children's Hospital, University of Calgary, Calgary, Canada AB T2T 5C7
}

(Correspondence should be addressed to J-P Chanoine; Email: jchanoine@cw.bc.ca)

\begin{abstract}
Objective: Ghrelin is secreted primarily by the stomach and circulates as both acylated and desacyl ghrelin. Acylated (but not desacyl) ghrelin stimulates appetite. Both concentrations are elevated in Prader-Willi syndrome (PWS), suggesting that ghrelin may contribute to hyperphagia and overweight in these subjects. We evaluated whether long-acting octreotide (Oct) decreases acylated and desacyl ghrelin concentrations, body mass, appetite and compulsive behaviour towards food in adolescents with PWS. Design: A 56-week prospective, randomized, cross-over trial.

Methods: Nine subjects with PWS (age 14.6 (10.8-18.9) years, body mass index (BMI) Z-score +1.9 (0.6-3.0)) received either Oct (30 mg) or saline i.m. every 4 weeks for 16 weeks and were switched over to the other treatment after a 24-week washout period.

Results: Eight subjects completed the study. Oct caused a decrease in both acylated ( $-53 \%)$ and desacyl $(-54 \%)$ fasting ghrelin concentrations $(P<0.05)$ but did not significantly affect BMI. Oct had no significant effect on peptide YY concentrations, appetite or compulsive behaviour towards food. Oct caused a decrease in insulin-like growth factor-I concentrations, an increase in HbAlc and transient elevation of blood glucose in two subjects. Three subjects developed gallstones.

Conclusions: Oct treatment caused a prolonged decrease in ghrelin concentrations in adolescents with PWS but did not improve body mass or appetite. Future intervention studies aiming at clarifying the role of ghrelin in PWS should focus on the administration of specific inhibitors of ghrelin secretion or ghrelin receptor activity that do not interfere with other appetite-regulating peptides.
\end{abstract}

European Journal of Endocrinology 159 381-388

\section{Introduction}

Obesity is a cardinal feature of Prader-Willi syndrome (PWS). It is characterized by hyperphagia, persistent hunger with increased caloric intake, decreased perception of satiety and compulsive behaviour that is primarily food related $(1,2)$. The treatment of obesity in PWS is difficult and requires a comprehensive multidisciplinary approach as well as constant involvement of the parents or caregivers with establishment of rigid structures to limit food intake and promote supervised physical activity.

Ghrelin is a peptide hormone mainly secreted by the stomach. It circulates as acylated and desacyl ghrelin. The presence of an acyl chain on the Ser 3 residue of ghrelin is necessary to activate the growth hormone (GH) secretagogue receptor that mediates the orexigenic action of ghrelin at the hypothalamic level. Accordingly, exogenous administration of acylated (but not desacyl) ghrelin increases appetite. An inverse correlation has been observed between circulating ghrelin and insulin concentrations, suggesting a role for ghrelin in glucose metabolism (3). In addition, ghrelin concentrations increase with fasting and decrease following a meal (4), suggesting a possible role in meal initiation. The exact role of endogenous ghrelin in humans remains unclear. In adult (5) and young $(3,6)$ obese subjects (without PWS), ghrelin concentrations are decreased compared with lean subjects suggesting that ghrelin does not play a causal role in the development of obesity. By contrast, subjects with PWS are characterized by elevated ghrelin concentrations despite their weight excess (7), raising the possibility that ghrelin may contribute to the food-seeking behaviour observed in these subjects. 
Somatostatin, a hormone that inhibits the secretion of $\mathrm{GH}$, insulin and gut hormones such as the anorexigenic peptide YY (PYY), markedly decreases ghrelin concentrations (8). In addition, repeated administration of a short-acting analogue of somatostatin was also shown to cause a decrease in circulating total ghrelin concentrations for up to 1 week (9). Whether this intervention also affects the acylated form of ghrelin, and whether a longer treatment duration decreases weight gain in these subjects is presently unknown. We hypothesized that therapy with the long-acting form of octreotide (Oct), a somatostatin analogue, would cause a prolonged decrease in ghrelin concentrations in subjects with PWS. The objectives of this pilot study were 1) to determine the effect of Oct treatment for 16 weeks on fasting and on post-glucose load plasma acylated and desacyl ghrelin concentrations and on weight gain, food-seeking behaviour and appetite and 2) to monitor the safety of Oct in subjects with PWS.

\section{Subjects and methods}

\section{Design and schedule}

Nine subjects (five males and four females) with PWS participated in this 56-week randomized, double-blind, cross-over trial. Inclusion criteria were: diagnosis of PWS confirmed by genetic testing, age $>10$ years and body mass index (BMI) $>85$ th centile for chronological age. Exclusion criteria were: gallstone on ultrasound or abnormal electrocardiogram (ECG) at baseline, pregnancy, previous use of Sandostatin LAR, medications known to affect food intake, type 2 diabetes, untreated hypothyroidism and severe rectal picking. The subjects were recruited from the endocrinology and genetics clinics at British Columbia Children's Hospital (Vancouver, $n=6$ ) and Alberta Children's Hospital (Calgary, $n=3$ ). The subjects were randomized into receiving 4 i.m. injections of $30 \mathrm{mg}$ Oct acetate (Sandostatin LAR, Novartis Pharmaceuticals; Oct phase) or saline (placebo phase, Pla) at 4-week intervals. After a 24-week washout period (1.5 times the time required for complete disappearance of Oct after a single injection (10)), the subjects were switched over to the other treatment modality. In order to ensure proper blinding to the medication (Sandostatin LAR is easily distinguished from saline), injections were performed in the absence of the parents by a nurse who was not otherwise involved in the study. The study was approved by the University of British Columbia Ethics Review Board ('ClinicalTrials.gov' Identifier: NCT00175305). We received consent for participation from the subjects' legal guardians and, when appropriate, assent from the subjects.

\section{Evaluations}

There were a total of 10 visits. Anthropometric measurements were performed at each visit. Hormonal and biochemical investigations, gallbladder ultrasound and nutritional and behavioural studies were performed prior to the first injection and 4 weeks after the last injection of each phase.

Body measurements and laboratory investigations Height and weight were measured in duplicate in light clothing without shoes. BMI (weight $(\mathrm{kg}) /$ height $(\mathrm{m})^{2}$ ) and BMI Z-score (using the least mean squares (LMS) method) were calculated (11). Body composition was assessed in both centres by dual-energy X-ray absorptiometry (DXA) using a Hologic QDR $4500 \mathrm{~W}$ bone densitometer.

Subjects were admitted between 0800 and $0900 \mathrm{~h}$ after a 12-h fast. An oral glucose tolerance test (OGTT) was performed $(1.75 \mathrm{~g} / \mathrm{kg}$ glucose, max $75 \mathrm{~g})$ during which blood was drawn for determination of glycosylated haemoglobin $(\mathrm{HbAlc})$ and insulin-like growth factor-I (IGF-I) (0 min), acylated and total ghrelin, PYY, and insulin and glucose (0 and $120 \mathrm{~min}$ ) concentrations. In addition, in five subjects, we were able to collect blood samples 30, 60 and 90 min following glucose ingestion. Blood was kept on ice until centrifugation $\left(4^{\circ} \mathrm{C}\right)$ and aliquots of plasma were stored at $-80^{\circ} \mathrm{C}$. Ghrelin, PYY, IGF-I and insulin determinations were batched and centralized. For ghrelin determination, $50 \mu \mathrm{l}$ phenylmethane-sulfonylfloride (10 mg/ml solution, Sigma) and $50 \mu \mathrm{l}$ of $1 \mathrm{M}$ hydrochloric acid were added to each $\mathrm{ml}$ plasma immediately following centrifugation. For PYY determination, aprotinin (Trasylol, $10000 \mathrm{KI} / \mathrm{ml}$, $50 \mu \mathrm{l} / \mathrm{ml}$ plasma; Bayer Inc.) was added to the EDTA tube prior to blood collection. Total (acylated + desacyl; \#GHRT-89HK, Linco Research, St Charles, MO, USA) and acylated (\#GHRA-88HK, Linco) ghrelin concentrations (12), PYY-like immunoreactivity (PYY3-36 plus PYY136) (13) and glucose and insulin concentrations (12) were determined as described previously. Desacyl ghrelin concentrations were calculated by subtraction (total minus acylated). IGF-I was determined by ELISA (DSL5600, Diagnostic Systems Laboratories, Webster, TX, USA; intraassay coefficient of variation $<7.1 \%)$. HbA1c was determined in Vancouver by latex immunoagglutination inhibition (DCA 2000+, Bayer Health Care) and in Calgary by immunoturbidimetry (Cobas Integra 700, Roche Diagnostics Corporation). As both assays are part of the National Glycohemoglobin Standardization Program (www.ngsp.org), the results were pooled and analyzed together.

Evaluation of food intake Food intake was assessed through a 3-day food record (Food Processor SQL nutrition and fitness software, ESHA Research, Salem, OR, USA, version $9.7,2005$ ) completed by the parent (and the subject if appropriate) during the week just prior to the beginning and end of each phase.

Psychometric assessment At four time points, the beginning and end of Pla and Oct phases, subjects and caregiver respondents completed a questionnaire 
battery assessing satiation, obsessive and compulsive observations, food-seeking behaviours, maladaptive behaviours (non-food related) and general competencies.

a. Child Behaviour Checklist (CBCL) for ages 6-18. The CBCL/6-18 is a norm-referenced, diagnostic and statistical manual (DSM)-oriented scale assessing competencies and maladaptive behaviour/problems. Our study focused on the results of the scale's maladaptive behaviour component, a 118 item forced choice index of internalizing behaviours such as being anxious or withdrawn, externalizing behaviours such as rule breaking and aggression, and total problems, a combination of internalizing and externalizing problems in addition to social, thought and attention problems (rev in (14)).

b. Child Yale-Brown Obsessive Compulsive Scale (CYBOCS). The CY-BOCS measures the severity and cluster type of compulsive behaviours and obsessive thoughts in subjects with obsessive-compulsive disorder (15). Compulsions and obsessions are organized into nine common clusters such as washing/cleaning and somatic problems. Questions demanding a high degree of self-awareness, i.e. those pertaining to control exerted over compulsive behaviour or degree of insight into obsessions and compulsions, were removed from our study due to caregiver informant versus subject responders.

c. Feeding Behaviour Questionnaire for PWS. We used a modified version of the Eating Disorders Examination questionnaire (16) developed by DeSantadina and Berall (University of Toronto, personal communication). The scale is a 14 item forced choice questionnaire assessing the presence and degree of maladaptive food-seeking behaviour; it is directed to parents/guardians. The modified questionnaire contains additional items on nausea.

d. Visual Analogue Scale (VAS). Evaluation of hunger was performed using a previously validated VAS for children with PWS (17). Four thermometer graphics displaying a temperature gradient corresponding to the intent/direction of the response were added to aid subjects with comprehension of the VAS. Questions include, 'How hungry do you feel?' 'How full do you feel' and 'How much food do you think you could eat?'.

\section{Statistical analysis}

Baseline data are expressed as mean (95\% confidence interval (CI)) or median (range). The test for order effect of the randomization (Oct or Pla in the first phase) showed that order did not affect the results and all data from each treatment group were therefore combined. Data were analyzed by comparing the changes that occurred in each group (Pla or Oct) during the intervention. For hormonal data (ghrelin, PYY, insulin and IGF-I), statistical analyses were performed using non-parametric tests for two (Wilcoxon test) or more (Friedman test) related samples. When more than two related samples were present, post hoc analysis was performed using Wilcoxon with Bonferroni correction. All other data were normally distributed and we performed paired $t$-tests (two samples) or ANOVA for repeated measures (more than two samples) followed by post hoc analysis using paired $t$-test. The relationship between the variables under study was assessed using the Pearson's coefficient of correlation $r . P$ value $<0.05$ was considered significant. Data were analyzed with SPSS version 15.0 (2006, SPSS Inc., Chicago, IL, USA).

\section{Results}

\section{Baseline characteristics of the subjects}

The baseline characteristics of the subjects are reported in Table 1. One subject was included despite a BMI on the 74 th centile because of severe food-seeking behaviour and major weight control difficulties. Six patients had a deletion on chromosome 15 and 3, a uniparental disomy. One subject dropped out at the beginning of the second phase, after receiving the first Oct injection, because of acute psychosis. Her baseline determinations are included in Table 1 but her results have otherwise not been analysed. None of the subjects had experienced spontaneous pubertal development. Four male subjects were on a stable dose of testosterone enanthate (range: 25-250 mg/month). One subject had been receiving human $\mathrm{GH}(0.15 \mathrm{mg} / \mathrm{kg}$ per week $)$

Table 1 Baseline characteristics of the subjects.

\begin{tabular}{lll}
\hline & Mean & \multicolumn{1}{c}{$\begin{array}{c}95 \% \\
\text { Confidence } \\
\text { interval }\end{array}$} \\
\hline Age (years) & 14.6 & $10.8-18.9$ \\
Height $(\mathrm{cm})$ & 147.1 & $132.2-162.9$ \\
Weight $(\mathrm{kg})$ & 68.3 & $45.6-98.4$ \\
BMl $\left(\mathrm{kg} / \mathrm{m}^{2}\right)$ & 31.8 & $23.2-51.0$ \\
BMI Z-score & 1.9 & $0.6-3.0$ \\
Fat mass $(\mathrm{kg})$ & 30.0 & $18.0-47.1$ \\
Body fat (\%) & 43.4 & $35.8-52.9$ \\
Fasting blood glucose $(\mathrm{mg} / \mathrm{dl})$ & 88 & $74-103$ \\
$2-\mathrm{h}$ blood glucose $(\mathrm{mg} / \mathrm{dl})$ & 105 & $77-160$ \\
HbA1c $(\%)$ & 5.1 & $4.5-5.8$ \\
& \multicolumn{1}{c}{ Median } & Range \\
Fasting acylated ghrelin $(\mathrm{pg} / \mathrm{ml})$ & 114 & $39-340$ \\
Fasting desacyl ghrelin $(\mathrm{pg} / \mathrm{ml})$ & 1327 & $792-2118$ \\
Fasting peptide $\mathrm{YY}(\mathrm{pmol} / \mathrm{l})$ & 23.1 & $15.7-45.6$ \\
Fasting insulin $(\mu \mathrm{U} / \mathrm{ml})$ & 8.4 & $2.2-21.2$ \\
Fasting IGF-I (ng/ml) & 254 & $177-569$ \\
\hline
\end{tabular}

Ghrelin: $\mathrm{pg} / \mathrm{ml} \times 0.296=\mathrm{pmol} / \mathrm{l}$. Peptide $Y Y(P Y Y): p g / m l \times 0.25=\mathrm{pmol} / \mathrm{l}$. IGF-I: $\mathrm{ng} / \mathrm{ml} \times 0.13=\mathrm{nmol} / \mathrm{l}$. Glucose: $\mathrm{mg} / \mathrm{dl} \times 0.056=\mathrm{mmol} / \mathrm{l}$. Insulin: $\mu \mathrm{U} / \mathrm{ml} \times 6.9=\mathrm{pmol} / \mathrm{l}$.

${ }^{\mathrm{a}}$ Excluding one subject on a stable dose of $\mathrm{GH}$. 
for 4 years while another started GH therapy 1 month prior to final evaluation $(0.3 \mathrm{mg} / \mathrm{kg}$ per week). One subject was on a stable dose of L-thyroxin $(75 \mu \mathrm{g} /$ day $)$.

\section{Ghrelin, PYY and glucose homeostasis}

Acylated ghrelin represented $13 \pm 4 \%$ of total ghrelin concentrations. There was a negative correlation between total ghrelin concentrations and BMI Z-score $(r=-0.77,95 \%$ CI: 0.21-0.95, $P=0.016)$. Compared with the Pla phase, Oct caused a marked decrease in fasting and 2-h post-glucose acylated ghrelin concentrations in all subjects and a decrease in fasting desacyl ghrelin concentrations in all but one subject. By contrast, Oct did not significantly affect fasting and 2-h post-glucose PYY concentrations (Table 2).

Fasting and 2-h blood glucose tended to increase more in the Oct compared with the Pla phase. Glycosylated haemoglobin decreased slightly during the Pla phase and increased in the Oct phase (Table 2). Two subjects (including one with glucose intolerance at screening) had a 2-h glucose value $>$ $11 \mathrm{mmol} / \mathrm{l}$ at the end of the Oct phase but this was resolved following Oct discontinuation.

In the five subjects in whom plasma samples were collected at regular intervals during the OGTT, Oct was associated with a loss of the physiological postprandial decrease in desacyl ghrelin. The change in desacyl ghrelin between 0 (fasting) and $30 \mathrm{~min}$ following glucose intake remained unchanged throughout the Pla phase. By contrast, during the Oct phase, this change went from $-294(-209$ to -409$) \mathrm{pg} / \mathrm{ml}$ at the beginning to +7 ( -37 to +46$) \mathrm{pg} / \mathrm{ml}$ following four injections of Oct $(P=0.043)$. There was no significant increase in PYY following glucose intake. Oct caused a significant decrease in 0 (fasting) to 30 min (peak) insulin response $(P=0.008)$.

\section{Weight, height, BMI, IGF-I and body composition}

Weight increased similarly during each phase ( $P=0.048$ from the beginning to end of the phase). Oct had no significant effect on weight, BMI or \% body fat (Table 2 and Fig. 1). There was no significant correlation between the magnitude of the ghrelin response to Oct (whether expressed as absolute changes in ghrelin concentrations or as percentage of the baseline concentrations) and weight or BMI changes. IGF-I concentrations decreased during the Oct compared with the Pla phase.

\section{Behaviour}

ANOVA for the various questionnaires assessing the changes in behavioural aspects of the subjects did not

Table 2 Changes in hormone concentrations, anthropometry and \% body fat during the placebo and octreotide phases.

\begin{tabular}{|c|c|c|c|}
\hline & Placebo & Octreotide & Significance \\
\hline \multicolumn{4}{|c|}{ Hormones (median (25th-75th centile)) } \\
\hline Acylated ghrelin (\%) & & & Friedman test $P=0.01$ \\
\hline Fasting & $-24(-49$ to +8$)$ & $-53(-82$ to -34$)$ & $P=0.05$ \\
\hline $2 \mathrm{~h}$ & $-28(-36$ to +15$)$ & $-64(-107$ to -58$)$ & $P=0.05$ \\
\hline Desacyl ghrelin (\%) & & & Friedman test $P=0.01$ \\
\hline Fasting & $3(-15$ to +9$)$ & $-54(-62$ to -46$)$ & $P=0.05$ \\
\hline $2 \mathrm{~h}$ & $-5(-13$ to +10$)$ & $-25(-30$ to -16$)$ & $P>0.1$ \\
\hline PYY (\%) & & & Friedman test $P>0.1$ \\
\hline $\begin{array}{l}\text { Fasting } \\
2 \mathrm{~h}\end{array}$ & $\begin{array}{l}-2(-23 \text { to }+25) \\
10(-7 \text { to }+28)\end{array}$ & $\begin{array}{l}-6(-20 \text { to }+9) \\
-20(-27 \text { to }+47)\end{array}$ & \\
\hline Insulin (\%) & & & Friedman test $P>0.1$ \\
\hline Fasting & $22(-25$ to +83$)$ & $-30(-36$ to -13$)$ & \\
\hline $2 \mathrm{~h}$ & $254(-109$ to +1222$)$ & $-32(-168$ to +96$)$ & \\
\hline IGF-I (\%) & $10(-4$ to +28$)$ & $-16(-25$ to -11$)$ & Wilcoxon test $P=0.036$ \\
\hline \multicolumn{4}{|c|}{ Glucose homeostasis (mean (95\% confidence interval)) } \\
\hline Glucose (mg/dl) & & & ANOVA $P=0.081$ \\
\hline Fasting & $+0.9(-4.1$ to +6.1$)$ & $+8.6(+2.3$ to +14.8$)$ & \\
\hline $2 \mathrm{~h}$ & $+6.1(-16.2$ to +28.4$)$ & $+33.5(-2.5$ to +70.0$)$ & \\
\hline HbA1c (\%) & $-0.1(-0.3$ to +0.1$)$ & $+0.2(0$ to +0.4$)$ & Paired $t$-test $P=0.009$ \\
\hline \multicolumn{4}{|c|}{ Body composition (mean (95\% confidence interval)) } \\
\hline Weight $(\mathrm{kg})$ & $+1.8(-0.2$ to +3.8$)$ & $+1.6(-0.4$ to +3.6$)$ & Paired $t$-test $P>0.1$ \\
\hline Height (cm) & $+0.36(-0.42$ to +1.15$)$ & $+0.48(-0.08$ to +1.03$)$ & Paired $t$-test $P>0.1$ \\
\hline $\operatorname{BMI}\left(\mathrm{kg} / \mathrm{m}^{2}\right)$ & $+0.8(-0.4$ to +2.0$)$ & $+0.6(-0.3$ to +1.6$)$ & Paired $t$-test $P>0.1$ \\
\hline BMI Z-score & $+0.19(-0.08$ to +0.12$)$ & $+0.35(-0.08$ to +0.15$)$ & Paired $t$-test $P>0.1$ \\
\hline Fat mass $(\mathrm{kg})^{\mathrm{a}}$ & $-0.3(-2.5$ to +1.9$)$ & $+0.4(-1.5$ to +2.2$)$ & Paired $t$-test $P>0.1$ \\
\hline Body fat $(\%)^{\mathrm{a}}$ & $-1.4(-0.5$ to +3.3$)$ & $+0.3(-1.6$ to +1.1$)$ & Paired $t$-test $P>0.1$ \\
\hline
\end{tabular}

Values represent the changes in a given variable from the beginning to the end of each phase (placebo or octreotide). For statistics, see 'Statistical analysis' section.

${ }^{\mathrm{a}}$ Excluding one subject who started $\mathrm{GH} 1$ month prior to the end of the Pla phase. 
show any significant effect of the intervention. Similarly, visual examination of the individual responses did not show any specific pattern consistent with an effect of the intervention (Fig. 2).

\section{Nutrition}

The intervention had no significant effect on the quantitative and qualitative composition of the diet. At baseline, mean $(95 \% \mathrm{CI})$ reported caloric intake was
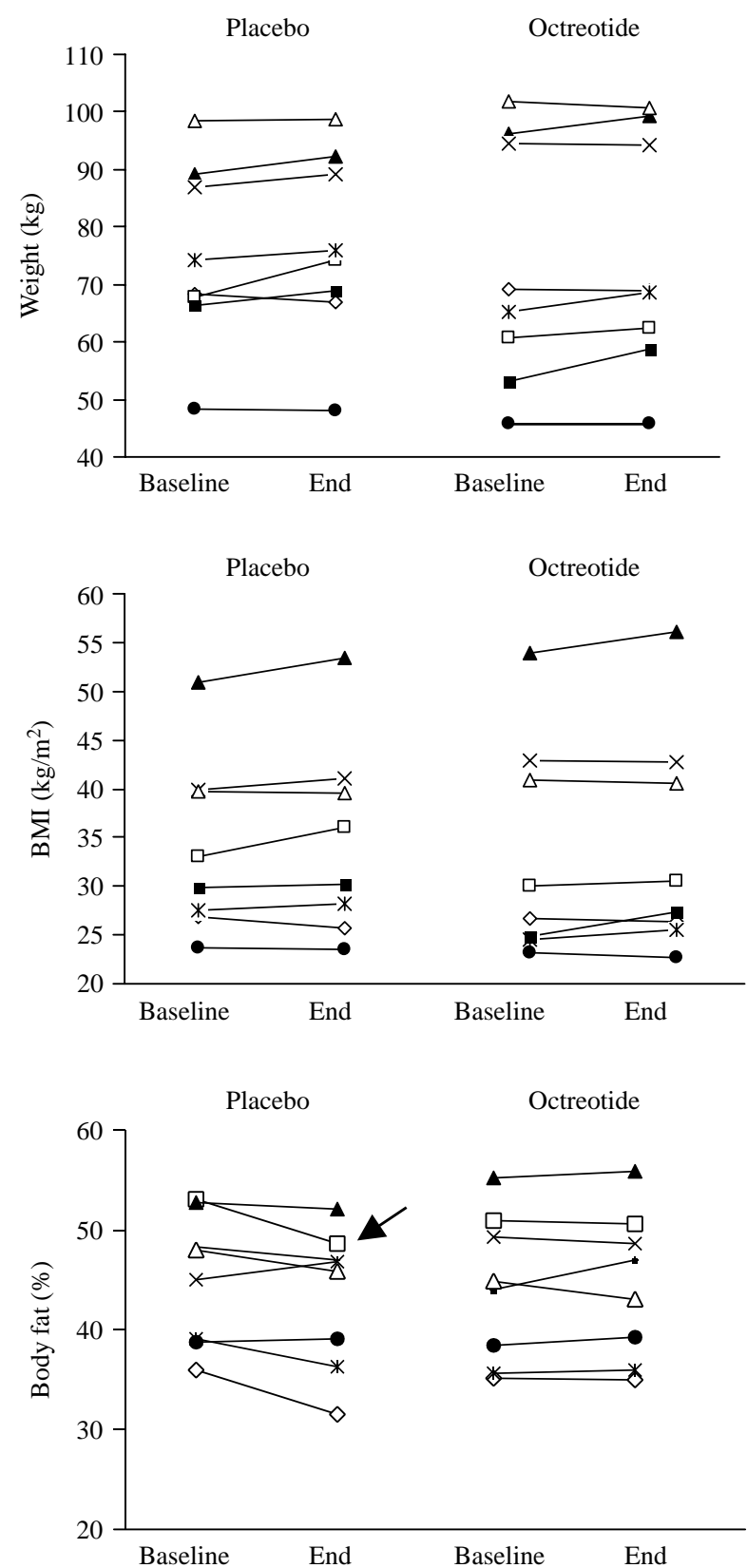

Figure 1 Individual values for body weight, $\mathrm{BMI}$ and \% body fat at baseline and at the end of the Pla and Oct phases in subjects with PWS. The arrow indicates the subject who started GH 1 month prior to the end of the Pla phase.
1445 (869-1892) cal, with 60 (49-64) \% carbohydrates, 20 (15-27) \% protein and 20 (9-33) \% fat.

\section{Gallbladder ultrasound}

Three subjects developed asymptomatic gallbladder abnormalities on the ultrasound by the end of the Oct phase and two of these required cholecystectomy 12-24 months after Oct discontinuation.
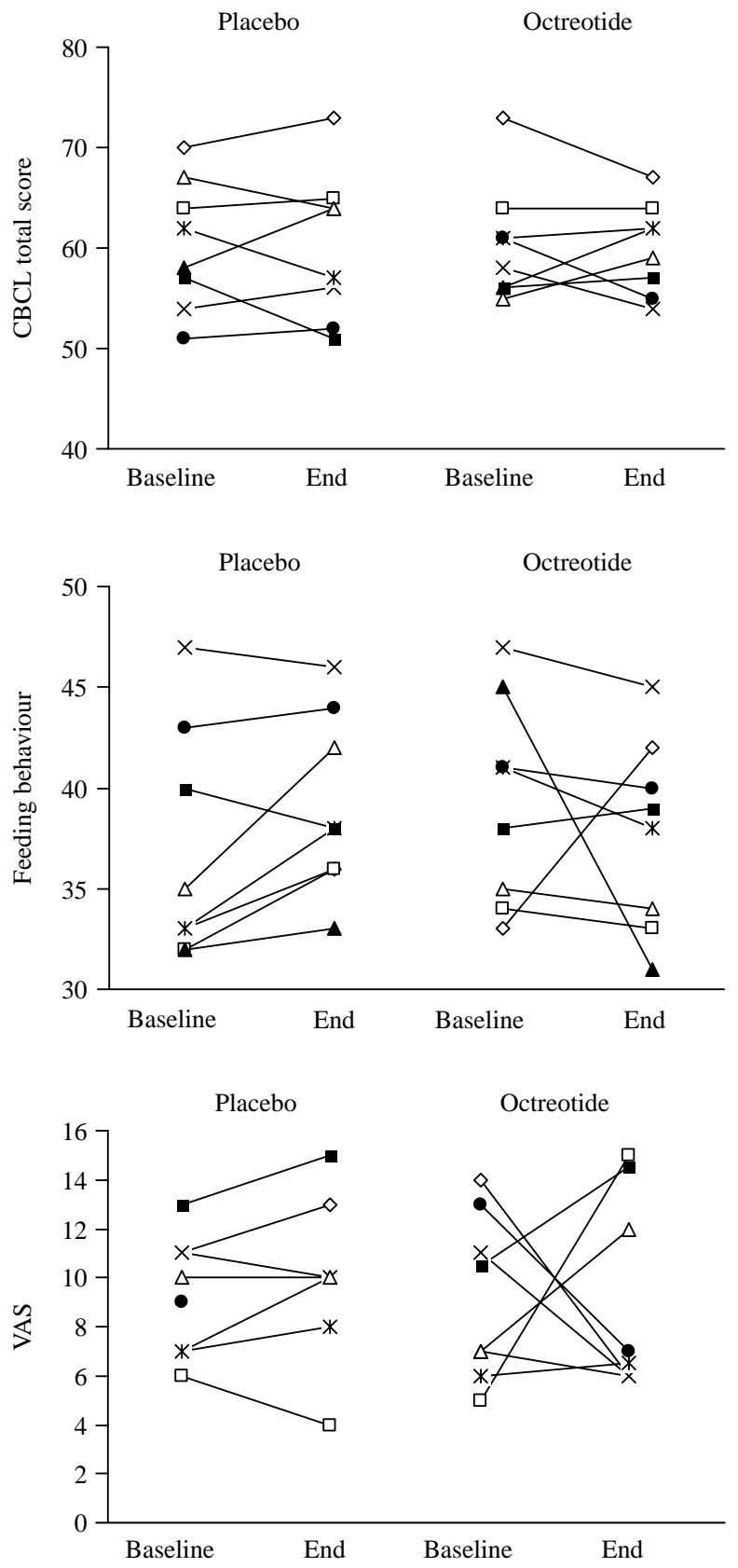

Figure 2 Individual values for the Child Behaviour Checklist (CBCL total score), feeding behaviour (Eating Disorders Examination questionnaire) and Visual Analogue Scale (VAS). 


\section{Discussion}

Medical care of adolescents with PWS is complicated and requires a multidisciplinary approach (18). Controlling the hyperphagia and weight excess associated with this condition remains one of the most difficult challenges of the intervention. The elevated total (7) and acylated (19) ghrelin concentrations observed in PWS contrast with the low values found in obese, nonPWS subjects and led us to hypothesize that suppression of ghrelin using long-acting analogues of somatostatin could provide an etiological treatment for the hyperphagia characteristic of PWS and contribute to the care of these subjects. This study demonstrates that Oct successfully decreased fasting and postprandial concentrations of both acylated and desacyl ghrelin for 16 weeks in these subjects. For unclear reasons, one subject failed to show a decrease in desacyl ghrelin (but not in acyl ghrelin). Contrasting with the changes in ghrelin, there were no changes in body weight, body composition, appetite or behaviour towards food.

In adult subjects with PWS, Oct infusion was associated with a $60 \%$ decrease in total ghrelin concentrations that were not associated with a decrease in appetite over a single meal (20). Using the dose of $5 \mu \mathrm{g}$ short-acting Oct $/ \mathrm{kg}$ body weight, s.c., three times a day for 1 week, Haqq et al. (9) observed a $67 \%$ decrease in ghrelin concentrations. Using a similar dose given as one injection every 4 weeks, our study is the first to investigate the effect of long-acting Oct on ghrelin in young subjects with PWS.

There are several potential explanations for our results. First, our study included a small number of subjects. As a consequence, despite the use of a crossover design, we could have missed modest decreases in weight or food intake. However, in contrast to nonspecific interventions characteristic of most obesity trials, this study had a specific target: excess ghrelin. If our hypothesis that ghrelin causes hyperphagia in PWS had been verified, we would have expected changes in food intake and behaviour that would be easily noticed, similar to the large and rapid changes observed in leptin-deficient subjects following leptin replacement (21). Second, the decrease in circulating ghrelin, known to mediate appetite regulation, could be too small to be perceived at the hypothalamic level and translate into clinically relevant effects. However, we did not observe a significant correlation between the degree of ghrelin suppression and the changes in weight. Third, Oct blunted the postprandial decrease in ghrelin concentrations, known to be associated with changes in appetite (22). Fourth, the increase in circulating ghrelin reported in PWS may not be present centrally or may not explain the abnormal hunger perceptions seen in these subjects (23). The gene encoding ghrelin is located on chromosome 3 in humans (7) while PWS is associated with the functional loss of paternally expressed genes located on chromosome 15 or uniparental disomy for maternal chromosome 15 (1). Whether these affected genes are part of a pathwayregulating ghrelin expression remains to be demonstrated. Alternately, increased appetite may be secondary to abnormal expression of non-ghrelin genes. For instance, it has recently been suggested that genes involved in the development of serotoninergic pathways are affected in PWS, which could potentially influence appetite $(24,25)$. Finally, while Oct decreases plasma concentrations of ghrelin, an orexigenic hormone, it also decreases the concentrations of anorexigenic hormones, such as insulin (26) and PYY (27). Because PYY regulation was previously shown to be abnormal in PWS (28), we focused on PYY, which increases rapidly in the circulation in response to a meal to signal satiety (3). In keeping with others, we observed a blunted PYY response to caloric intake in subjects with PWS (29), which could cause an overall decrease in satiety. In contrast to Tan et al. (20) who investigated adult subjects with PWS, we found no effect of Oct on PYY concentrations, suggesting that in our study, suppressed PYY concentrations were not an explanation for the lack of effect of Oct on appetite.

Oct treatment is associated with known side effects (30). Prolonged Oct treatment decreases insulin secretion and causes impaired glucose tolerance. Our results showed that Oct increased $\mathrm{HbAlc}$ and suppressed insulin response. In addition, two subjects developed blood glucose concentrations in the diabetic range following Oct. Discontinuation of Oct was followed by a normalization of the glycemia. Oct also causes a reduction in bile production and gallbladder contractility with increases in the risk of cholesterol gallstones. In children with hypothalamic obesity, longacting Oct at the dose of $40 \mathrm{mg}$ every month for 6 months was associated with bile sludge and/or gallstones in $37 \%$ of the subjects (31). In our study, gallbladder abnormalities were also present in $37 \%$ of subjects after only 16 weeks of treatment at a lower dose and two subjects underwent a cholecystectomy several months after Oct discontinuation. The absence of an obvious weight loss effect and the presence of significant complications observed in this pilot study do not point towards a positive risk benefit ratio for Oct in subjects with PWS.

We used a cross-over design to evaluate the effect of Oct on ghrelin, body mass, behaviour and safety in our subjects. This design has limitations. For instance, the drop out of one subject at the beginning of the second phase made it impossible to analyse any of the data pertaining to this subject. However, it also has advantages that were felt to be very important in our setting. Firstly, a design where each subject serves as his/her own control and receives the placebo/drug in random order makes it possible to obtain meaningful results with a smaller number of subjects despite large inter-individual variations in ghrelin concentrations. 
Secondly, this was the first time that long-acting Oct was administered in subjects with PWS and we felt that, from a safety point of view, it was important to expose as few subjects as possible in this pilot study. A parallel design would have required the inclusion of a larger number of subjects.

In conclusion, sustained decreases in acylated and desacyl ghrelin concentrations for 16 weeks following Oct administration did not affect weight, appetite or compulsive behaviour towards food in subjects with PWS. While this does not completely rule out a role for ghrelin in the pathophysiology of appetite in PWS, future intervention studies should aim at clarifying the role of ghrelin and focus on the administration of agents that specifically inhibit ghrelin secretion or its action at the receptor level, do not interfere with other appetiteregulating peptides, and are well tolerated.

\section{Declaration of interest}

The authors declare that there is no conflict of interest that would prejudice the impartiality of this scientific work.

\section{Funding}

The study was supported by a grant from the Prader-Willi Syndrome Association (USA). Sandostatin LAR $^{\circledR}$ was a gift from Novartis Canada.

\section{Acknowledgements}

Kathleen De Waele was the recipient of an ESPE clinical research Fellowship (Novo Nordisk). We would like to acknowledge the team at the Center for Hip Health and Musculoskeletal Research, Vancouver Coastal Health Research Institute for acquiring the DXA scans. Our thanks also go to Dr Elizabeth Mickelson for helpful discussions, to Mabel Tan and Anne Gregnier (Vancouver) and Wendy Schwarz and Laura Kaminsky (Calgary) for their help in assessing the subjects and to Christine Lovatt, Nutritional Analyst. We wish to thank all subjects and their families for their participation.

\section{References}

1 Bittel DC \& Butler MG. Prader-Willi syndrome: clinical genetics, cytogenetics and molecular biology. Expert Reviews in Molecular Medicine 20057 1-20.

2 Dimitropoulos A, Feurer ID, Roof E, Stone W, Butler MG, Sutcliffe J \& Thompson T. Appetitive behavior, compulsivity, and neurochemistry in Prader-Willi syndrome. Mental Retardation and Developmental Disabilities Research Reviews 20006 125-130.

3 Stock S, Leichner P, Wong AC, Ghatei MA, Kieffer TJ, Bloom SR \& Chanoine JP. Ghrelin, peptide YY, glucose-dependent insulinotropic polypeptide, and hunger responses to a mixed meal in anorexic, obese, and control female adolescents. Journal of Clinical Endocrinology and Metabolism 200590 2161-2168.

4 Cummings DE, Purnell JQ, Frayo RS, Schmidova K, Wisse BE \& Weigle DS. A preprandial rise in plasma ghrelin levels suggests a role in meal initiation in humans. Diabetes 200150 1714-1719.

5 Tschop M, Weyer C, Tataranni PA, Devanarayan V, Ravussin E \& Heiman ML. Circulating ghrelin levels are decreased in human obesity. Diabetes 200150 707-709.
6 Mackelvie KJ, Meneilly GS, Elahi D, Wong AC, Barr SI \& Chanoine JP. Regulation of appetite in lean and obese adolescents after exercise: role of acylated and desacyl ghrelin. Journal of Clinical Endocrinology and Metabolism 200792 648-654.

7 DelParigi A, Tschop M, Heiman ML, Salbe AD, Vozarova B, Sell SM, Bunt JC \& Tataranni PA. High circulating ghrelin: a potential cause for hyperphagia and obesity in Prader-Willi syndrome. Journal of Clinical Endocrinology and Metabolism 200287 5461-5464.

8 Barkan AL, Dimaraki EV, Jessup SK, Symons KV, Ermolenko M \& Jaffe CA. Ghrelin secretion in humans is sexually dimorphic, suppressed by somatostatin, and not affected by the ambient growth hormone levels. Journal of Clinical Endocrinology and Metabolism $2003 \mathbf{8 8} 2180-2184$.

9 Haqq AM, Stadler DD, Rosenfeld RG, Pratt KL, Weigle DS, Frayo RS, LaFranchi SH, Cummings DE \& Purnell JQ. Circulating ghrelin levels are suppressed by meals and octreotide therapy in children with Prader-Willi syndrome. Journal of Clinical Endocrinology and Metabolism $2003 \mathbf{8 8} 3573-3576$.

10 Chen T, Miller TF, Prasad P, Lee J, Krauss J, Miscik K, Kalafsky G \& McLeod JF. Pharmacokinetics, pharmacodynamics, and safety of microencapsulated octreotide acetate in healthy subjects. Journal of Clinical Pharmacology 200040 475-481.

11 National Health and Nutrition Examination Survey. Percentile Data Files with LMS Values. www.cdc.gov/nchs/about/major/ nhanes/growthcharts/datafiles.htm. Accessed Jan 182008.

12 Mackelvie KJ, McKay HA, Khan KM \& Crocker PR. A school-based exercise intervention augments bone mineral accrual in early pubertal girls. Journal of Pediatrics 2001139 501-508.

13 Batterham RL, Cowley MA, Small CJ. Herzog H, Cohen MA, Dakin CL, Wren AM, Brynes AE, Low MJ, Ghatei MA, Cone RD \& Bloom SR. Gut hormone PYY(3-36) physiologically inhibits food intake. Nature $2002 \mathbf{4 1 8} 650-654$.

14 Achenbach TM \& Ruffle TM. The Child Behavior Checklist and related forms for assessing behavioral/emotional problems and competencies. Pediatrics in Review 200021 265-271.

15 Scahill L, Riddle MA, McSwiggin-Hardin M, Ort SI, King RA, Goodman WK, Cicchetti D \& Leckman JF. Children's Yale-Brown Obsessive Compulsive Scale: reliability and validity. Journal of the American Academy of Child and Adolescent Psychiatry 199736 $844-852$.

16 Cooper Z \& Fairburn CG. The eating disorders examination: a semi-structured interview for the assessment of the specific psychopathology of eating disorders. International Journal of Eating Disorders 19876 1-8.

17 Holland AJ, Treasure J, Coskeran P, Dallow J, Milton N \& Hillhouse E. Measurement of excessive appetite and metabolic changes in Prader-Willi syndrome. International Journal of Obesity and Related Metabolic Disorders 199317 527-532.

18 Eiholzer U \& Whitman BY. A comprehensive team approach to the management of patients with Prader-Willi syndrome. Journal of Pediatric Endocrinology and Metabolism 200417 1153-1175.

19 Paik KH, Choe YH, Park WH, Oh YJ, Kim AH, Chu SH, Kim SW, Kwon EK, Han SJ, Shon WY \& Jin DK. Suppression of acylated ghrelin during oral glucose tolerance test is correlated with whole body insulin sensitivity in children with Prader-Willi syndrome. Journal of Clinical Endocrinology and Metabolism 2006 91 1876-1881.

20 Tan TM, Vanderpump M, Khoo B, Patterson M, Ghatei MA \& Goldstone AP. Somatostatin infusion lowers plasma ghrelin without reducing appetite in adults with Prader-Willi syndrome. Journal of Clinical Endocrinology and Metabolism $2004 \mathbf{8 9}$ 4162-4165.

21 Farooqi IS, Jebb SA, Langmack G, Lawrence E, Cheetham $\mathrm{CH}$, Prentice AM, Hughes IA, McCamish MA \& O'Rahilly S. Effects of recombinant leptin therapy in a child with congenital leptin deficiency. New England Journal of Medicine 1999341 879-884.

22 Cummings DE, Frayo RS, Marmonier C, Aubert R \& Chapelot D. Plasma ghrelin levels and hunger scores in humans initiating meals voluntarily without time- and food-related cues. American Journal of Physiology. Endocrinology and Metabolism 2004287 E297-E304. 
23 Hinton EC, Holland AJ, Gellatly MS, Soni S, Patterson M, Ghatei MA \& Owen AM. Neural representations of hunger and satiety in Prader-Willi syndrome. International Journal of Obesity 200630 313-321.

24 Tauber M, Conte Auriol F, Moulin P, Molinas C, Delagnes V \& Salles JP. Hyperghrelinemia is a common feature of Prader-Willi syndrome and pituitary stalk interruption: a pathophysiological hypothesis. Hormone Research 200462 49-54.

25 Zanella S, Watrin F, Mebarek S, Marly F, Roussel M, Gire C, Diene G, Tauber M, Muscatelli F \& Hilaire G. Necdin plays a role in the serotonergic modulation of the mouse respiratory network: implication for Prader-Willi syndrome. Journal of Neuroscience 200828 1745-1755.

26 Lustig RH, Hinds PS, Ringwald-Smith K, Christensen RK, Kaste SC, Schreiber RE, Rai SN, Lensing SY, Wu S \& Xiong X. Octreotide therapy of pediatric hypothalamic obesity: a doubleblind, placebo-controlled trial. Journal of Clinical Endocrinology and Metabolism $2003 \mathbf{8 8} 2586-2592$.

27 O'Keefe SJ, Haymond MW, Bennet WM, Oswald B, Nelson DK \& Shorter RG. Long-acting somatostatin analogue therapy and protein metabolism in patients with jejunostomies. Gastroenterology $1994 \mathbf{1 0 7} 379-388$.
28 Butler MG, Bittel DC \& Talebizadeh Z. Plasma peptide YY and ghrelin levels in infants and children with Prader-Willi syndrome. Journal of Pediatric Endocrinology and Metabolism 2004 17 1177-1184.

29 Gimenez-Palop O, Gimenez-Perez G, Mauricio D, GonzalezClemente JM, Potau N, Berlanga E, Trallero R, Laferrere B \& Caixas A. A lesser postprandial suppression of plasma ghrelin in Prader-Willi syndrome is associated with low fasting and a blunted postprandial PYY response. Clinical Endocrinology 2007 66 198-204.

30 Heikenen JB, Pohl JF, Werlin SL \& Bucuvalas JC. Octreotide in pediatric patients. Journal of Pediatric Gastroenterology and Nutrition 200235 600-609.

31 Lustig RH, Peterkova V, Skorodok J, De Schepper J, VelasquezMieyer P, Hollander A, Anderson J, Darby C, Tavorah R \& Tran L. A global, randomized, double-blind, placebo-controlled trial of octreotide-LAR in the treatment of pediatric hypothalamic obesity. Hormone Research 200564275 (P2-949).

Received 15 June 2008

Accepted 19 June 2008 